\title{
Resistance to heat and cold stress in Drosophila melanogaster: intra and inter population variation in relation to climate
}

\author{
D Guerra ${ }^{1}$, S Cavicchi $^{1 *}$, RA Krebs ${ }^{2}$ V Loeschcke $^{3}$ \\ ${ }^{1}$ Dipartimento di Biologia evoluzionistica sperimentale, Università di Bologna, \\ via Selmi 3, 40126-Bologna, Italy; \\ 2 Department of Organismal Biology and Anatomy, The University of Chicago, \\ 1027 East 57th Street, Chicago, IL 60637, USA; \\ 3 Department of Ecology and Genetics, University of Aarhus, Ny Munkegade, \\ Bldg 540 DK - 8000 Aarhus C, Denmark
}

(Received 13 June 1996; accepted 9 June 1997)

\begin{abstract}
Summary - Genetic variation for resistance to high and low temperature stress and wing size was examined within and among four Drosophila melanogaster populations from temperate (Denmark and Italy) and subtropical areas (Canary Islands and Mali). The temperature of induction of the heat shock response was examined by conditioning flies to different high temperatures in the range 34 to $40^{\circ} \mathrm{C}$ prior to exposing them to heat shock $\left(41.5^{\circ} \mathrm{C}\right.$ for $\left.0.5 \mathrm{~h}\right)$. Stress resistance appeared to be related to climate: populations from warm regions were the most heat tolerant and those from cold regions were the most cold tolerant. This trend suggests that natural selection in the wild at non-extreme temperature can lead to a correlated response in tolerance to extreme temperature. Wing size varied significantly, and generally was larger for flies from more northerly populations. Populations varied genetically in all traits measured. Among traits, a positive correlation was present between heat-shock resistance with conditioning and resistance to cold, and the correlation was suggestive between heat-shock resistance with and without a conditioning treatment, but no correlation was indicated between cold resistance and heat resistance of non-conditioned individuals. Wing size was not correlated with any stress type. The results suggest that different groups of genes are involved in the resistance at extreme temperature ranges.
\end{abstract}

acclimation / heat shock resistance / cold shock resistance / wing size

Résumé - Résistance au stress de chaleur et de froid chez Drosophila melanogaster : variation entre et intrapopulations en fonction du climat. La variation génétique pour la résistance au stress à haute ou basse température et la taille de l'aile ont été examinées

* Correspondence and reprints 
dans quatre populations de Drosophila melanogaster provenant des régions tempérées (Danemark et Italie) et subtropicales (îles Canaries et Mali). La température d'induction de la réponse au choc thermique a été examinée après conditionnement à températures différentes (de $34 \grave{a} 40^{\circ} \mathrm{C}$ ) avant le traitement proprement dit $\left(41.5^{\circ} \mathrm{C}\right.$ pendant $\left.30 \mathrm{~min}\right)$. La résistance au stress est en relation avec le climat: les populations des régions chaudes montrent la plus grande résistance à la chaleur et celles des régions froides, la plus grande résistance au froid. Ce résultat suggère que la sélection naturelle dans un milieu tempéré peut amener à une réponse corrélée pour la tolérance au stress thermique. On a observé une variation significative de la taille de l'aile, qui augmente avec la latitude. Une variabilité génétique pour tous les caractères considérés a été aussi mise en évidence dans toutes les populations. La résistance à la chaleur après conditionnement a été en corrélation positive avec la résistance au froid et une corrélation presque significative a été trouvée entre mouches conditionnées et non pour la résistance au choc thermique. D'un autre côté, on n'a pas trouvé de corrélation entre la résistance à la chaleur et la résistance au froid chez les mouches non conditionnées. La taille de l'aile n'a été corrélée avec aucun stress thermique. Les résultats suggèrent que des groupes différents de gènes contrôlent la résistance à différentes températures extrêmes.

climatisation / résistance à la chaleur / résistance au froid / taille de l'aile

\section{INTRODUCTION}

Variation in resistance to environmental stress has been observed among related species and populations of Drosophila from climatically different regions, particularly for heat (Hosgood and Parsons, 1968; Parsons, 1979; Coyne et al, 1983), and cold shock resistance (Jefferson et al, 1974; Tucic, 1979; Marinkovic et al, 1980; Kimura, 1982; Fukatami, 1984; Heino and Lumme, 1989; Hoffmann and Watson, 1993), and this variation appears to be an evolutionary response to the environment (Hoffmann and Parsons, 1991; Loeschcke et al, 1994). Success in selecting for stress resistance indicates that a significant additive genetic component also is present within populations (Morrison and Milkman, 1978; Kilias and Alahiotis, 1985; Quintana and Prevosti, 1990 b; Jenkins and Hoffmann, 1994; Krebs and Loeschcke, 1996).

Maintenance of Drosophila populations at different temperatures in the laboratory indicates that adaptation to non- extreme temperatures may yield correlated responses to tolerance to extreme high temperatures (Stephanou and Alahiotis, 1983; Huey et al, 1991, Cavicchi et al, 1995), and that these correlated effects include changes in the induction of the heat shock response (Cavicchi et al, 1995). Conditioning individuals with a short exposure to high temperatures before heat shock increases resistance relative to that without a conditioning treatment, and multiple treatments may increase survival more than a single treatment (Loeschcke et al, 1994; Krebs and Loeschcke, 1995). The molecular basis of the regulation of the heat shock response (Maresca and Lindquist, 1991; Morimoto et al, 1990, 1994), which occurs across all kingdoms of life (Landry et al, 1982; Vierling, 1991; Parsell and Lindquist, 1994), provides a link between conditioning treatments that induce heat shock protein production and those increasing survival under thermal stress or other stress types (Landry et al, 1982; Lindquist, 1986; Brown, 1991).

Here, we investigated heat and cold resistance and the induction of thermotolerance in populations of $D$ melanogaster from temperate and subtropical areas. 
Our aim was to identify if this resistance relates to the climate of the localities of origin. If so, natural selection in the wild at non-extreme temperature has led to a genetically correlated response in tolerance to extreme temperature. The question of general interest is: does selection for increased fitness at a given range of temperature lead to a genetically correlated response in the resistance to extreme temperature close to the optimum? If so, are the same or different groups of genes involved in the adaptation to the optimum and/or to either hot or cold temperature extremes (Huey and Kingsolver, 1993)? Our previous works on chromosomal analysis of laboratory populations of Drosophila adapted to different temperatures (Cavicchi et al, 1989, 1995) showed that the genes responsible for adaptation to intermediate temperature are located on chromosomes different from those controlling survivorship at extreme heat, although heat resistance evolved as a correlated response to natural selection at non-extreme temperature. Does the same relationship occur in natural populations from different climatic areas? Here we analysed the survivorship of genotypes from different populations at high and low temperature extremes. The correlation between performances of different isofemale lines could be a useful tool to assess whether the same or different evolutionary mechanisms are at work in the laboratory and in the wild.

Because phenotypic differences in body size may have impact on resistance to temperature extremes (Quintana and Prevosti, 1990a; Loeschcke et al, 1994), wing size variation among populations was compared and the correlation with stress resistance analysed. Size variations may not be easily separated from variation in resistance, as geographical clines for body size follow temperature gradients in several Drosophila species (Stalker and Carson, 1947; Prevosti, 1955; Misra and Reeve, 1964; David et al, 1977; David and Capy, 1988; Capy et al, 1993; Imasheva et al, 1994). A genetic and phenotypic relationship between body size and temperature also has been shown in the laboratory (Anderson, 1973; Cavicchi et al, 1985, 1989), where adult body size negatively correlated with temperature (Starmer and Wolf, 1989; Thomas, 1993), except at temperatures approaching the limit for development (David et al, 1994).

\section{MATERIALS AND METHODS}

\section{Origin of populations}

The founder populations derived from 50-100 females of $D$ melanogaster collected in nature from Hov, Denmark in late October, 1992; from Bologna, Italy in October, 1993; from southwestern Teneriffe, Canary Islands; and from Bamako, southern Mali in December, 1993. Table I describes differences in thermal extremes for each region.

Single females were put in vials. From those identified as melanogaster, ten isofemale lines for each population were established. The lines were reared in bottles with discrete generations, avoiding overcrowding. Mass populations were obtained by pooling lines of each population in cages with overlapping generations. Flies were maintained on a medium of yeast, sugar, cornmeal and agar at $25^{\circ} \mathrm{C}$. Experiments were initiated in the spring of 1994. 
Table I. Mean minimum and maximum temperature in the colder (winter) and warmer (summer) months at different localities.

\begin{tabular}{rlcrr}
\hline & Mali & Canary I & Italy & Denmark \\
\hline Winter & & & & \\
$\min$ & 20 & 16 & -1.0 & -1.5 \\
$\max$ & 25 & 21 & 6.1 & 3.9 \\
Summer & & & & \\
$\min$ & 24.4 & 19 & 17.7 & 8.9 \\
$\max$ & 31.4 & 26 & 30.9 & 19.5 \\
\hline
\end{tabular}

\section{Heat resistance and induced thermotolerance}

Flies were heat shocked using the procedures adopted in previous experiments (Cavicchi et al, 1995). Males and females were collected using ether anaesthesia and partitioned into about 50 flies per vial. Females and males were considered together because, under our experimental conditions, they survived similarly in replicated experiments at different shock temperatures. Flies were restrained at the bottom of weighted plastic vials (without food) by sponge plugs and were shocked in a water bath at $41.5^{\circ} \mathrm{C}$ for $30 \mathrm{~min}$. Care was taken to treat only 4-7-day-old flies as resistance declines in older individuals (Quintana and Prevosti, 1990b; Dahlgaard et al, 1995). During treatment, humidity was not controlled within vials, but the water bath was a saturated humidity environment that minimised any desiccation effects (Maynard Smith, 1956; Hoffmann and Parsons, 1989). Following heat shock, flies were transferred to new vials containing food, and survivorship was scored $24 \mathrm{~h}$ later. As almost all individuals were knocked-down, survivorship was taken as the proportion of individuals that reacted when touched with forceps. Heat shock was applied both on mass populations and on the individual isofemale lines. For comparing populations, three replicate measurements were obtained in each of two independent blocks. For isofemale lines, two replicates were subjected to the heat treatment, but, owing to the bath size, at different times for various populations. Data were arcsin transformed before statistical analysis.

To determine differences among the four mass populations for the threshold temperature that induces thermotolerance, two replicates of 50 flies each in one or two independent blocks were conditioned for $5 \mathrm{~min}$ at one of a graded series of temperatures ranging from 34 to $40^{\circ} \mathrm{C}$, returned to $25^{\circ} \mathrm{C}$ for $0.5 \mathrm{~h}$ and then heat shocked as described (Cavicchi et al, 1995). As only two conditioning temperatures could be tested at any one time, non-conditioned control flies from each mass population were also simultaneously heat shocked. Therefore, induction of thermotolerance was measured for each population as the difference between the proportion of flies that survived heat shock with conditioning in each replicate and the mean for each population that survived without conditioning. A total of 44 vials were non-conditioned (12 for Mali and Denmark, 10 for Canary Islands and Bologna) while 78 vials were conditioned (18 for Denmark and Italy, 20 for Canary Islands and 22 for Mali).

For isofemale lines, a treatment condition was chosen prior to heat shocking lines that maximally induced thermotolerance for each population. Individuals of 
the Canary Island and Danish populations therefore were first exposed to a slightly lower temperature $\left(36^{\circ} \mathrm{C}\right)$ than those from Mali or Bologna $\left(38^{\circ} \mathrm{C}\right)$. In this case also, the preconditioning and heat shock treatments were performed separately for each population.

\section{Cold resistance}

Flies both from mass populations and isofemale lines were subjected to cold treatment of $0^{\circ} \mathrm{C}$ for $48 \mathrm{~h}$ in a thermostatic chamber with saturated humidity. The initial temperature was $20-22^{\circ} \mathrm{C}$, and the temperature declined to $0^{\circ} \mathrm{C}$ in about $15 \mathrm{~min}$. As for heat shock, about 50 flies were placed in empty plastic vials. Two replicates in three blocks were treated for comparing populations. For comparing lines, two replicates for each isofemale line were cold shocked at the same time, while, as for heat shock, various populations were treated at different times. Again, resistance was scored as the proportion of flies reacting when touched with forceps and the data were arcsin transformed before statistical analysis.

\section{Wing size}

After rearing individuals of each isofemale line in uncrowded conditions, the right wing of five females per line was removed and mounted on slides, from which wing area was measured (MTV3 program of Data Crunch Corporation, South Clemente, $\mathrm{CA})$. The overall mean was taken as the population mean size.

\section{Statistical analysis}

In the first experiment, significance of population differences for heat resistance, cold resistance (after arcsin transformation) and wing size was tested by Anova and a posteriori hypotheses of pair-wise differences were examined using Tukey's multiple comparisons test. Significance of differences among populations and different acclimatization treatments in the second experiment was tested in a two-way fixed effects Anova (SAS, 1989).

Intraclass correlations $(t)$ were derived from Anova only for wing size. For survivorship, which is a threshold trait, we followed the method proposed by Robertson and Lerner (1949) in which:

$$
t=\left[\chi^{2}-(N-1)\right] / n_{0}
$$

where $\chi^{2}$ is the heterogeneity in the $2 \times N$ table, as flies can be classified only as dead or alive, $N$ is the number of isofemale lines and

$$
n_{0}=\sum n_{i}-\left(\sum n_{i}^{2} / \sum n_{i}\right)-(N-1)
$$

where $n$ is the number of flies heat or cold shocked for each isofemale line. In our experiment, $N=10$ isofemale lines and $n \geqslant 50$ flies for each line, averaging two replicates of more than 50 flies, as they cannot be assigned to different experimental blocks. 
The observed variance in binomial data is correlated with the mean. Hence correction for comparing intraclass correlations from different treatments and populations can be made by transforming $t$ on the probit scale by multiplying $t$ by

$$
[\bar{p}(1-\bar{p})] / z^{2}
$$

where $\bar{p}$ is the fraction which survives (or dies) and $z$ is the ordinate of the normal curve at the point where the tail area is equal to $\bar{p}$.

Standard errors of intraclass correlations were computed following Falconer (1989) for wing size and Fisher (1941) for survivorships.

Overall $t$ values were reported on the basis of a pooling procedure both for stress resistances and wing size.

Standard parametric correlation coefficients among the four traits were obtained for each population using the mean stress resistance (after arcsin transformation) or size of each line. Overall correlations also were reported on the basis of the pooled variance-covariance matrix.

\section{RESULTS}

\section{Interpopulation analysis}

Mean survivorship (\%) for each population following either a heat or cold treatment, and mean wing size of females are presented in table II (rows identified by No 1). For cold resistance, variation among blocks was significant $(P<0.01)$. For neither heat nor cold shock was the population by block interaction significant. Variation due to the origin of populations was highly significant for all three traits $(P<0.001)$, and two by two comparisons (Tukey's multiple comparisons test) revealed significant differences between geographic areas (table II). Heat resistance was higher for flies from the Canary Islands and from Mali than for flies from Denmark and Italy; while cold resistance was highest for flies from Italy, followed by those from Denmark, Mali and the Canary Islands, respectively, although significance levels overlapped between some populations. Wing size was significantly larger for flies from Italy and Denmark than for those from the Canary Islands population, and wing size of flies from Mali was significantly smaller than that of all other populations.

Mean survivorship differences between flies heat shocked with and without conditioning at temperatures from 34 to $40^{\circ} \mathrm{C}$ are presented in table IIIA. The two populations subjected to higher summer temperatures in nature (Mali and Italy) showed a larger induction of thermotolerance at higher temperatures than the other two $\left(38\right.$ versus $\left.36^{\circ} \mathrm{C}\right)$. The increase in survival was not significantly different among the four populations conditioned with any of the temperatures. Similar results for all conditioning treatments enabled us to pool across temperatures and test differences in survival among populations either with or without conditioning (table IIIB).

Conditioning significantly increased survival, and as before, the populations varied in survival after thermal stress, while the population by treatment interaction was not significant. Survival of flies from the Canary Islands population and from Mali was significantly higher than that for flies from Denmark, and flies from the Italy population had the lowest survival (table II, rows identified by No 2). All 
Table II. Survivorship (\%土 se) of mass populations and lines after heat-shock at $41.5^{\circ} \mathrm{C}$ for $0.5 \mathrm{~h}$ with and without conditioning, after cold treatment at $0^{\circ} \mathrm{C}$ for $48 \mathrm{~h}$ and wing size (in $\mathrm{mm}^{2}$ ), in experiment 1,2 and 3 .

\begin{tabular}{lcccc}
\hline Treatment & Mali & Canary I & Italy & Denmark \\
\hline Heat & & & & \\
1. mass (not conditioned) & $85.5 \pm 2.5 \mathrm{a}$ & $75.2 \pm 8.1 \mathrm{a}$ & $55.3 \pm 6.5 \mathrm{~b}$ & $57.7 \pm 3.8 \mathrm{~b}$ \\
2. mass (conditioned) & $61.8 \pm 5.7 \mathrm{a}$ & $69.5 \pm 6.8 \mathrm{a}$ & $37.6 \pm 5.1 \mathrm{c}$ & $51.4 \pm 5.6 \mathrm{~b}$ \\
2. mass (not conditioned) & $46.1 \pm 5.9 \mathrm{a}$ & $45.0 \pm 3.4 \mathrm{a}$ & $24.7 \pm 4.4 \mathrm{~b}$ & $32.6 \pm 3.3 \mathrm{~b}$ \\
3. lines (conditioned) & $71.4 \pm 4.2$ & $88.4 \pm 3.6$ & $53.6 \pm 3.0$ & $60.7 \pm 4.8$ \\
3. lines (not conditioned) & $37.8 \pm 5.2$ & $19.6 \pm 4.2$ & $21.6 \pm 4.8$ & $20.9 \pm 5.2$ \\
Cold & & & & \\
1. mass & $48.5 \pm 2.9 \mathrm{bc}$ & $44.3 \pm 2.2 \mathrm{c}$ & $58.4 \pm 5.3 \mathrm{a}$ & $53.0 \pm 3.7 \mathrm{ab}$ \\
3. lines & $46.8 \pm 1.7$ & $46.6 \pm 4.1$ & $63.6 \pm 4.2$ & $47.0 \pm 2.1$ \\
Size & & & & \\
wing size & $1.42 \pm 0.01 \mathrm{c}$ & $1.49 \pm 0.02 \mathrm{~b}$ & $1.64 \pm 0.01 \mathrm{a}$ & $1.59 \pm 0.01 \mathrm{a}$ \\
\hline
\end{tabular}

Comparisons are given only between comparable groups. Equal letters denote groups not statistically different based on Tukey's multiple comparisons test. For mass populations, three replicates of about 50 flies in two independent blocks were considered for heat and two replicates in three blocks were considered for cold shock (experiment 1); in experiment 2 , a total of 44 vials were not conditioned (12 for Mali and Denmark, 10 for Canary Islands and Bologna) while 78 vials were conditioned (18 for Denmark and Italy, 20 for Canary Islands and 22 for Mali). For lines (experiment 3), two replicates of about 50 flies for 10 isofemale lines were exposed to thermal stress. Wing size refers to five female right wings from ten isofemale lines.

values are lower than those of the previous experiment (No 1) owing to a slight increase (less than 0.5 of a degree) of the water bath temperature.

\section{Intrapopulation analyses}

From analyses on individual isofemale lines, mean values (table II, rows identified by No 3) and intraclass correlations (table IV) were obtained in each population for heat shock resistance with and without conditioning, for cold resistance, and for wing size.

Comparisons among populations were not given as each population also represents a different experimental block. In spite of that, with the exception of the Canary Islands population subjected to heat shock without conditioning, the interpopulation differences were comparable to those of the previous experiments.

Intraclass correlations were not different among stress types, but those for wing size were consistently larger. The Mali population, for heat shock resistance and wing size, and the Italian population, for cold resistance, showed the lowest intraclass correlations. 
Table III. A) Survivorship differences $(\% \pm$ se) for adult flies of four populations either first conditioned at different temperatures and then exposed to a thermal stress or flies not conditioned before exposure to stress ( $N$ for all means $=2$ or 4 vials). B) Anova for the test of differences between populations, treatments and their interaction.

\begin{tabular}{|c|c|c|c|c|}
\hline \multicolumn{5}{|l|}{ A) } \\
\hline $\begin{array}{l}\text { Conditioning } \\
\text { temperature }\left({ }^{\circ} \mathrm{C}\right)\end{array}$ & Mali & Canary $I$ & Italy & Denmark \\
\hline 34 & $7.3 \pm 2.1$ & $9.6 \pm 12.3$ & $10.1 \pm 7.1$ & $-2.0 \pm 4.9$ \\
\hline 35 & $20.1 \pm 2.5$ & $22.5 \pm 11.0$ & $9.8 \pm 4.5$ & $21.5 \pm 9.4$ \\
\hline 36 & $15.4 \pm 6.1$ & $40.0 \pm 4.3$ & $4.8 \pm 3.8$ & $29.8 \pm 2.1$ \\
\hline 37 & $13.1 \pm 3.6$ & $25.6 \pm 8.8$ & $19.4 \pm 7.1$ & $23.0 \pm 13.8$ \\
\hline 38 & $32.6 \pm 1.0$ & $28.4 \pm 10.0$ & $27.4 \pm 2.2$ & $16.4 \pm 5.7$ \\
\hline 39 & $11.1 \pm 10.0$ & $20.1 \pm 5.0$ & $14.6 \pm 1.4$ & $26.9 \pm 6.3$ \\
\hline 40 & $10.9 \pm 6.9$ & $25.6 \pm 1.2$ & $4.5 \pm 2.7$ & $16.2 \pm 1.8$ \\
\hline \multicolumn{5}{|l|}{ B) } \\
\hline Sources of variation & $d f$ & $M S$ & $F$ & $P$ \\
\hline Populations & 3 & 0.454 & 10.5 & 0.001 \\
\hline $\begin{array}{l}\text { Conditioned versus not } \\
\text { conditioned }\end{array}$ & 1 & 1.108 & 25.7 & 0.001 \\
\hline Interaction & 3 & 0.031 & 0.7 & NS \\
\hline Residual & 114 & 0.043 & & \\
\hline
\end{tabular}

Table IV. Intraclass correlations ( $t$ se) of isofemale lines for survivorship after exposure to thermal stress either without or with a conditioning treatment, survivorship after a cold treatment and of wing size for four populations.

\begin{tabular}{lccccc}
\hline Trait & Mali & Canary I & Italy & Denmark & overall \\
\hline $\begin{array}{l}\text { Heat } \\
\text { (not conditioned) }\end{array}$ & $0.055 \pm 0.035$ & $0.114 \pm 0.058$ & $0.218 \pm 0.092$ & $0.141 \pm 0.068$ & $0.140 \pm 0.068$ \\
$\begin{array}{l}\text { Heat } \\
\text { (conditioned) }\end{array}$ & $0.081 \pm 0.045$ & $0.102 \pm 0.054$ & $0.219 \pm 0.093$ & $0.097 \pm 0.052$ & $0.125 \pm 0.063$ \\
Cold & $0.198 \pm 0.086$ & $0.139 \pm 0.067$ & $0.045 \pm 0.030$ & $0.106 \pm 0.055$ & $0.124 \pm 0.062$ \\
Wing size & $0.156 \pm 0.153$ & $0.789 \pm 0.098$ & $0.420 \pm 0.174$ & $0.464 \pm 0.171$ & $0.567 \pm 0.149$ \\
\hline
\end{tabular}

\section{Correlations among stress types and wing size}

Table $\mathrm{V}$ gives correlation coefficients between each pair of traits separately for each population and the overall correlations. At the population level, a significant correlation is observed between cold and heat shock resistance without conditioning in the Canary Islands population and between cold, wing size and heat shock 
Table V. Correlations $(r)$ between survivorship of different isofemale lines after exposure to thermal stress either without or with a conditioning treatment, survivorship after a cold treatment and wing size $(\mathrm{df}=8)$. Overall correlations are also given $(\mathrm{df}=32)$.

\begin{tabular}{llcrr}
\hline & & $\begin{array}{c}\text { Heat } \\
\text { (conditioned) }\end{array}$ & Cold & Wing size \\
\hline Heat (not conditioned) & Ma & 0.194 & -0.046 & -0.446 \\
& CI & 0.488 & $0.640^{*}$ & -0.544 \\
& It & 0.517 & -0.094 & 0.195 \\
& Dk & 0.199 & -0.081 & 0.404 \\
Overall & & $0.379^{*}$ & 0.104 & -0.077 \\
Heat (conditioned) & Ma & & 0.249 & 0.214 \\
& CI & & 0.467 & -0.295 \\
& It & & 0.365 & -0.121 \\
Overall & Dk & & $0.726^{* *}$ & $0.626^{*}$ \\
Cold & & & $0.417^{* *}$ & -0.142 \\
& Ma & & & -0.280 \\
& CI & & & -0.039 \\
& It & & & 0.369 \\
Overall & Dk & & & 0.269 \\
\hline
\end{tabular}

${ }^{*} P<0.05 ;{ }^{* *} P<0.01$.

resistance with conditioning in the Danish population. The analysis of covariance showed homogeneity among populations for the correlations between any pair of traits. The overall correlations, based on the pooled variances-covariances within populations, revealed that body size is not correlated with any stress type. Heat shock resistance with conditioning and cold shock resistance were correlated significantly and positively. A positive correlation between heat shock resistance with and without conditioning approached significance.

\section{DISCUSSION}

We investigated heat and cold resistance and the induction of thermotolerance in four populations of $D$ melanogaster, two from temperate and two from subtropical areas. Our aim was to evaluate i) the amount of genetic variability for different resistance traits and ii) their correlations; to identify whether iii) this resistance relates to the climate of the localities of origin and to determine whether iv) body size, which varies latitudinally, correlates at an intrapopulational level with resistance to temperature extremes.

Both within and among natural populations of $D$ melanogaster, genetic variation for survival at extreme temperatures is present, as well as for wing size, as also 
shown in the same and other Drosophila species by the authors quoted in the introduction to this work (Morrison and Milkman, 1978; Stephanou and Alahiotis, 1983; Quintana and Prevosti, 1990b; Jenkins and Hoffmann, 1994;. Tucic, 1979; Heino and Lumme, 1989 for temperature stresses; David and Capy, 1988; Capy et al, 1993, 1994 for size).

Intraclass correlations for isofemale lines estimate the genetic component of variance in a broad sense, including the additive, dominance, interaction and maternal components. When the additive variance is the prevailing component, the intraclass correlation includes half the heritability (Parsons, 1983). Direct estimates of heritability for survivorship under temperature stress in $D$ melanogaster are reported for cold shock by Tucic (1979) after long-term artificial selection on a population captured near Belgrade. He reported an estimate of $14 \%$ on adult flies, slightly lower than the value we obtain by averaging our four populations $(25 \%)$, but similar to the average of the two populations from temperate climates (15\%). For heat resistance we found heritability estimates of $25-28 \%$. Other direct estimates of heritability in this species are available only for knockdown temperature $(28 \%$; Huey et al, 1992). Experiments of indirect selection for heat survivorship (Stephanou and Alahiotis, 1983) confirmed that $D$ melanogaster possesses genetic resources to survive heat shock. For wing size, our estimates are similar to those reported by Capy et al (1994), with the exception of the Canary Islands population whose heritability exceeded $1(t=0.789)$. Wings of one isofemale line were consistently $20 \%$ shorter than the population mean. A single mutational event rather than quantitative variation may have caused this result. In the absence of this line, the intraclass correlation reduces to 0.49 , which is in line with other estimates.

For heat resistance in the Mali population and cold resistance in the Italian population, the lowest level of genetic variation and the maximum performance for these traits were observed. Also, the highest levels of genetic variation were found for the reverse comparison, cold resistance in the Mali population and heat resistance in the Italian population, where minimal performance was observed. Populations subjected to novel stress conditions often exhibit genetic variance at the highest levels (Hoffmann and Parsons, 1991). In general, the low level of variation in the Mali population, may reflect a relatively homozygous population following continuous directional selection for adaptation to heat extremes in nature (Parsons, 1983), though, for morphological traits, tropical populations show phenotypic variability larger than that exhibited by temperate populations and genetic variability that is almost the same (Capy et al, 1993).

Relative performance under heat and cold stress seemed related to the mean summer maximum temperature and the mean winter minimum temperature, respectively, for the four areas from which the flies were collected (comparing tables I and II). Clear differences were present only between very separate geographic regions. For most traits, differences between Mali and the Canary Islands or between Italy and Denmark were small, although wing size of Mali flies was smaller than that of flies from the Canary Islands. Perhaps behavioural traits that enable escape from unfavourable climatic conditions (Jones et al, 1987) are possible within a given temperature range and these reduce physiological differences between populations. Migration by fruit trading also could be relevant and give a reason for the relatively small size and resistance to cold of the Danish flies. Independent samples from each 
locality would have given more information for a comparison of relative thermal resistance in relation to the climatic conditions at the sample sites. However, we chose to keep up the number of geographic populations and traits instead of increasing sample number per locality.

The populations differed much more for heat than for cold resistance, a result that could depend either on the kind of treatment performed or upon different reaction norms to hot or cold temperature extremes.

The dependence of heat tolerance on the temperature at which a given population evolves has been well documented for populations adapted to different temperatures in the laboratory (Stephanou and Alahiotis, 1983; Huey et al, 1991; Cavicchi et al, 1995). Populations held at warmer temperatures may also show genetic differences for induction of thermotolerance, expressing the heat shock response at a higher temperature than those adapted to cold (Cavicchi et al, 1995). This trend suggests that natural selection in the wild at non-extreme temperature has led to a genetically correlated response in tolerance to extreme temperature, but that adaptation to one part of the thermal performance curve reduces adaptation at temperature extremes farther away. Previous work on relative chromosomal contributions to fitness components suggests that different groups of genes are involved for adaptation at intermediate temperature (Cavicchi et al, 1989) and resistance to extreme heat (Cavicchi et al, 1995). The present results, though not concerning intermediate temperatures, suggest that different groups of genes are important at the two extremes.

However, the correlation between heat shock resistance with conditioning and cold shock resistance in lines derived from natural populations was significant, suggesting that similar groups of genes may affect resistance at the two temperature extremes. Perhaps this relationship is due to a general hardiness or weakness of some lines that is independent of the shock response. Inbreeding is expected within isofemale lines and uncontrolled genetic drift or inbreeding may lead to positive associations among fitness traits (Dahlgaard et al, 1995).

The performances of different isofemale lines with or without conditioning show a low correlation, suggesting that the role of heat shock genes is unimportant for heat tolerance when a population is rapidly subjected to a potentially lethal heat stress $\left(41.5^{\circ} \mathrm{C}\right.$ for $0.5 \mathrm{~h}$ without conditioning). Molecular data support this observation, in that the maximal transcription level of a more inducible heat shock gene (hsp70 ) is reached after about half an hour after a severe heat treatment, while for others (hsp-82, -27) the maximum is observed after a longer time (DiDomenico et al, $1982 \mathrm{a}, \mathrm{b})$.

Suggestions on the mechanistic basis underlying how evolution in a population at intermediate temperature may affect tolerance to extreme temperature stress are, however, speculative. Nevertheless, studies of enzymes suggest that natural selection at different temperatures can be associated with variation in their kinetic parameters (Alahiotis, 1982; Hoffmann and Parsons, 1991; Somero, 1995) in such a way that enzymes show a greater efficiency under the conditions an organism normally encounters.

For the minimum temperature for induction of thermotolerance, the four $D$ melanogaster populations, which come from very different regions, were similar. This was not expected on the basis of our previous observations on laboratory 
populations adapted to different temperature optima (Cavicchi et al, 1995). These response types may be a general rule across species, and relate to the activation of heat shock genes (Lindquist and Craig, 1988; Huey and Bennett, 1990). The heat shock response is a physiologically plastic response to deal with stress, and in natural variable environments, induction temperatures may change little. Therefore, above some threshold temperature, the level of acclimation that occurs may be similar.

\section{ACKNOWLEDGEMENTS}

The research was supported by a grant from MURST (Italy) to S Cavicchi. The stay of $\mathrm{R}$ Krebs in Aarhus was funded through a grant from the Danish Natural Science Research Council (No 11-9639-2). The authors are grateful to R Huey for reading the manuscript and for valuable suggestions and to Vittoria La Torre for help in the experimental work.

\section{REFERENCES}

Alahiotis SN (1982) Adaptation of Drosophila enzymes to temperature. IV. Natural selection at the alcohol dehydrogenase locus. Genetics $59,81-87$

Anderson WW (1973) Genetic divergence in body size among experimental populations of Drosophila pseudoobscura kept at different temperatures. Evolution 27, 278-284

Brown IR (1991) Hyperthermia, tissue injury and other traumatic events. In: Heat Shock (B Maresca, S Lindquist, eds), Springer-Verlag, Berlin, 291--297

Capy P, Pla E, David JR (1993) Phenotypic and genetic variability of morphometric traits in natural populations of Drosophila melanogaster and D simulans. I. Geographic variations. Genet Sel Evol 25, 517-536

Capy P, Pla E, David JR (1994) Phenotypic and genetic variability of morphometric traits in natural populations of Drosophila melanogaster and D simulans. II. Withinpopulation variation. Genet Sel Evol 26, 15-28

Cavicchi S, Guerra D, Giorgi G, Pezzoli C (1985) Temperature related divergence in experimental populations of Drosophila melanogaster. I. Genetic and developmental basis of wing size and shape variations. Genetics 109, 665-689

Cavicchi S, Guerra D, Natali V, Pezzoli C, Giorgi G (1989) Temperature related divergence in experimental populations of Drosophila melanogaster. II. Correlation between fitness and body dimensions. J Evol Biol 2, 235-251

Cavicchi S, Guerra D, La Torre V, Huey RB (1995) Chromosomal analysis of heatshock tolerance in Drosophila melanogaster evolving at different temperatures in the laboratory. Evolution 49, 676-684

Coyne JA, Bundgaard J, Prout T (1983) Geographic variation of tolerance to environmental stress in Drosophila pseudoobscura. Am Nat 122, 474-488

Dahlgaard J, Krebs RA, Loeschcke V (1995) Inbreeding and heat shock tolerance in Drosophila buzzatii. Heredity 74, 157-163

David JC, Boquet C, De Scheemaeker-Louis M (1977) Genetic latitudinal adaptation of Drosophila melanogaster: new discriminative biometrical traits between European and Equatorial African populations. Genet Res 30, 247-255

David JC, Capy P (1988) Genetic variation of Drosophila melanogaster natural populations. Trends Genet 4, 89-95

David JR, Moreteau B, Gauthier JP, Petavy G, Stockel A, Imasheva AG (1994) Reaction norms of size characters in relation to growth temperature in Drosophila melanogaster: an isofemale lines analysis. Genet Sel Evol 26, 229-251 
DiDomenico BJ, Bugaisky GE, Lindquist S (1982a) The heat shock response is selfregulated at both the transcriptional and posttranscriptional levels. Cell 31, 593-603

DiDomenico BJ, Bugaisky GE, Lindquist S (1982b) Heat shock and recovery are mediated by different translational mechanisms. Proc Natl Acad Sci USA 79, 6181-6185

Falconer DS (1989) Introduction to Quantitative Genetics. Longman, London, 3rd ed

Fisher RA (1941) Statistical Methods for Research Workers. Oliver and Boyd, Edinburgh, 8th ed

Fukatami A (1984) Cold temperature resistance in Drosophila lutescens and D takahashii. Jpn J Genet 59, 61-70

Heino R, Lumme J (1989) Inheritance of cold shock tolerance in hybrids of Drosophila virilis and Drosophila lummei. Genetica $79,17-25$

Hoffmann AA, Parsons PA (1989) Selection for increased desiccation resistance in Drosophila melanogaster: additive genetic control and correlated responses for other stresses. Genetics 122, 837-845

Hoffmann AA, Parsons PA (1991) Evolutionary Genetics and Environmental Stress. Oxford Science Publications, Oxford

Hoffmann AA, Watson M (1993) Geographical variation in acclimation responses of Drosophila to temperature extremes. Am Nat 142, S93-S113

Hosgood SMW, Parsons PA (1968) Polymorphism in natural populations of Drosophila for the ability to withstand temperature shocks. Experientia 24, 727-728

Huey RB, Bennett AF (1990) Physiological adjustments to fluctuating thermal environments: an ecological and evolutionary perspective. In: Stress Proteins in Biology and Medicine (RI Morimoto, A Tissieres, C Georgopoulos, eds), Cold Spring Harbor Press, Cold Spring Harbor, NY, 37-59

Huey RB, Partridge L, Fowler K (1991) Thermal sensitivity of Drosophila melanogaster responds rapidly to laboratory natural selection. Evolution 45, 751-756

Huey RB, Kingsolver JG (1993) Evolution of resistance to high temperature in ectotherms. Am Nat 141, S21-S46

Huey RB, Crill WD, Kingsolver JG, Weber KE (1992) A method for rapid measurement of heat or cold resistance of small insects. Funct Ecol 6, 489-494

Imasheva AG, Bubli OA, Lazebny OE (1994) Variation in wing length in Eurasian natural populations of Drosophila melanogaster. Heredity 72, 508-514

Jefferson MC, Crumpacker DW, Williams JS (1974) Cold temperature resistance, chromosomal polymorphism and interpopulation heterosis in Drosophila pseudoobscura. Genetics 76, 807-822

Jenkins NL, Hoffmann AA (1994) Genetic and maternal variation for heat resistance in Drosophila from the field. Genetics 137, 783-789.

Jones JS, Coyne JA, Partridge L (1987) Estimation of the thermal niche of Drosophila melanogaster using a temperature-sensitive mutation. Am Nat 130, 83-90

Kilias G, Alahiotis SN (1985) Indirect thermal selection in Drosophila melanogaster and adaptive consequences. Theor Appl Genet 69, 645-650

Kimura MT (1982) Inheritance of cold-hardiness and sugar content in two closely related species, Drosophila takahashii and D lutescens. Jpn J Genet 57, 575-580

Krebs RA, Loeschcke V (1995) Costs and benefits of activation of the heat shock response in Drosophila melanogaster. Funct Ecol 8, 730-737

Krebs RA, Loeschcke V (1996) Acclimation and selection for increased resistance to thermal stress in Drosophila buzzatii. Genetics 142, 471-479

Landry J, Bernier D, Chrétien P, Nicole LM, Tanguay RM, Marceau N (1982) Synthesis and degradation of heat shock proteins during development and decay of thermotolerance. Cancer Res 42, 2457-2461 
Lindquist S (1986) The heat-shock response. Annu Rev Biochem 55, 1151-1191

Lindquist S, Craig EA (1988) The heat-shock proteins. Annu Rev Genet 22, 631-677

Loeschcke V, Krebs RA, Barker JSF (1994) Genetic variation for resistance and acclimation to high temperature stress in Drosophila buzzatii. Biol J Linn Soc 52, 83-92

Maresca B, Lindquist S (1991) Heat Shock. Springer-Verlag, Berlin

Marinkovic D, Tucic N, Kekic V (1980) Genetic variation and ecological adaptation. Genetica 52/53, 249-262

Maynard Smith J (1956) Temperature tolerance and acclimatization in Drosophila subobscura. J Genet 54, 85-96

Misra RK, Reeve ECR (1964) Clines in body dimensions in populations of Drosophila pseudoobscura. Genet Res 5, 240-256

Morimoto RI, Tissiéres A, Georgopoulos C (1990) Stress Proteins in Biology and Medicine, Cold Spring Harbor Laboratory Press, Cold Spring Harbor, NY

Morimoto RI, Tissiéres A, Georgopoulos C (1994) The Biology of Heat Shock Proteins and Molecular Chaperones. Cold Spring Harbor Laboratory Press, Cold Spring Harbor, NY

Morrison WW, Milkman R (1978) Modification of heat resistance in Drosophila by selection. Nature $273,49-50$

Parsell DA, Lindquist S (1994) Heat shock proteins and stress tolerance. In: The Biology of Heat Shock Proteins and Molecular Chaperones (RI Morimoto, A Tissiéres, C Georgopoulos, eds), Cold Spring Harbor Laboratory Press, 457-494

Parsons PA (1979) Resistance of the sibling species Drosophila melanogaster and Dosophila simulans to high temperatures in relation to humidity: evolutionary implications. Evolution 33, 131-136

Parsons PA (1983) The Evolutionary Biology of Colonizing Species. Cambridge University Press, New York

Prevosti A (1955) Geographical variability in quantitative traits of Drosophila subobscura. Cold Spring Harbor Symp Quant Biol 20, 294-299

Quintana A, Prevosti A (1990 a) Genetic and environmental factors in the resistance of Drosophila subobscura adults to high temperature shock. I. Breeding temperature and crowding. Theor Appl Genet 79, 103-107

Quintana A, Prevosti A (1990 b) Genetic and environmental factors in the resistance of Drosophila subobscura adults to high temperature shock. II. Modification of heat resistance by indirect selection. Theor Appl Genet $80,847-851$

Robertson A, Lerner IM (1949) The heritability of all-or-none traits: viability of poultry. Genetics 34, 395-411

SAS Institute Inc (1989) SAS/Stat User's Guide, Cary, NC

Somero GN (1995) Protein and temperature. Ann Rev Physiol 57, 43-68

Stalker HD, Carson HL (1947) Morphological variation in natural populations of Drosophila robusta. Evolution 1, 237-248

Starmer WT, Wolf LL (1989) Causes of variation in wing loading among Drosophila species. Biol J Linn Soc 37, 247-261

Stephanou G, Alahiotis SN (1983) Non-Mendelian inheritance of heat-sensitivity in Drosophila melanogaster. Genetics 103, 93-107

Thomas RH (1993) Ecology of body size in Drosophila buzzatii: untangling the effects of temperature and nutrition. Ecol Entomol 18, 84-90

Tucic N (1979) Genetic capacity for adaptation to cold resistance at different developmental stages of Drosophila melanogaster. Evolution 33, 350-358

Vierling E (1991) The roles of heat shock proteins in plants. Ann Rev Plant Physiol Plant Mol Biol 42, 579-620 